\section{Check for updates}

Cite this: J. Mater. Chem. B, 2021 9, 939

Received 1st September 2020 , Accepted 8th December 2020

DOI: 10.1039/d0tb02124e

rsc.li/materials-b

\title{
Electrospinning for healthcare: recent advancements
}

\author{
Karolina Dziemidowicz, ${ }^{\mathrm{a}}$ Qingqing Sang, ${ }^{\text {bc }}$ Jinglei Wu, (D) ${ }^{\mathrm{b}}$ Ziwei Zhang, ${ }^{\mathrm{a}}$ \\ Fenglei Zhou, ${ }^{\text {ad }}$ Jose M. Lagaron, ${ }^{e}$ Xiumei Mo, (DD ${ }^{b}$ Geoff J. M. Parker, ${ }^{d}$ \\ Deng-Guang Yu, (D) ${ }^{f}$ Li-Min Zhu (D) ${ }^{b}$ and Gareth R. Williams (DD *a
}

\begin{abstract}
Electrospinning is a simple route to generate polymer-based fibres with diameters on the nano- to micronscale. It has been very widely explored in biomedical science for applications including drug delivery systems, diagnostic imaging, theranostics, and tissue engineering. This extensive literature reveals that a diverse range of functional components including small molecule drugs, biologics, and nanoparticles can be incorporated into electrospun fibres, and it is possible to prepare materials with complex compartmentalised architectures. This perspective article briefly introduces the electrospinning technique before considering its potential applications in biomedicine. Particular attention is paid to the translation of electrospinning to the clinic, including the need to produce materials at large scale and the requirement to do so under Good Manufacturing Practice conditions. We finish with a summary of the key current challenges and future perspectives.
\end{abstract}

\section{Introduction}

The electrospinning (ES) technique has attracted increasing attention for pharmaceutical applications in recent years. ${ }^{1-9}$
A Web of Knowledge search for "electrospinning AND drug" (performed on 18/08/2020) reveals publication numbers rising year on year from the first reports in 2002 (two papers) through interest picking up by 2010 (115 publications) to 506 papers in

${ }^{a}$ UCL School of Pharmacy, University College London, 29-39 Brunswick Square, London WC1N 1AX, UK. E-mail: g.williams@ucl.ac.uk

${ }^{b}$ College of Chemistry, Chemical Engineering and Biotechnology, Donghua University, Shanghai 201620, China

${ }^{c}$ Department of Surgery, Shanghai Key Laboratory of Gastric Neoplasms, Shanghai Institute of Digestive Surgery, Ruijin Hospital, Shanghai Jiao Tong University School of Medicine, Shanghai 200025, China

${ }^{d}$ Centre for Medical Image Computing, UCL Computer Science, University College London, 90 High Holborn, London WC1V 6LJ, UK

${ }^{e}$ Novel Materials and Nanotechnology Group, Institute of Agrochemistry and Food Technology, Spanish Council for Scientific Research, Valencia 46100, Spain

${ }^{f}$ School of Materials Science \& Engineering, University of Shanghai for Science and Technology, 516 Jungong Road, Shanghai 200093, China

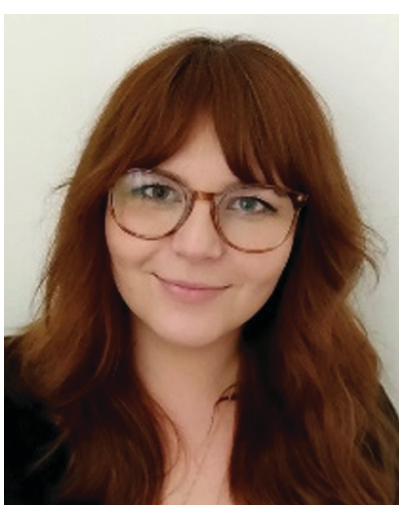

Karolina Dziemidowicz
Karolina is a final year PhD researcher on the EPSRC Centre for Doctoral Training in Advanced Therapeutics and Nanomedicines (UCL School of Pharmacy). She obtained her MPharm degree from King's College London in 2015. During her undergraduate studies, Karolina undertook her MPharm dissertation at Utrecht University (Pharmaceutics Department), working on drug-eluting bronchotracheal stents. She is a practising pharmacist and completed her pre-registration training at AstraZeneca (Macclesfield, UK). Her research focuses on the development of polymer-based biomaterials for enhancement of protein drug delivery and immunotherapy.

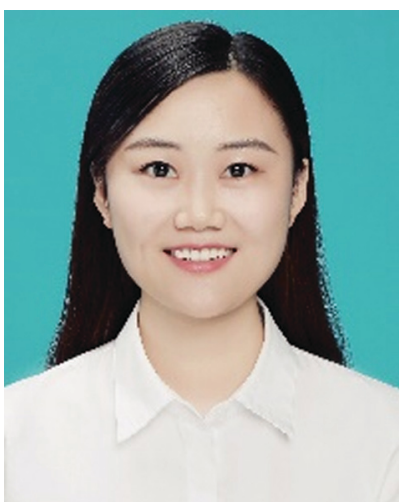

Qingqing Sang
Qingqing works as a medical technician at Ruijin Hospital, which is affiliated to the Medical College of Shanghai Jiaotong University. She graduated with an MSc from the College of Chemistry, Chemical Engineering and Biotechnology at Donghua University in 2018. Her research interests include coaxial electrospinning, anti-cancer biomaterials, and bioinformatics in cancer research. 
2019. In essence, ES represents a novel pharmaceutical drying technology: it involves the use of electricity to solidify a polymer solution or melt. ${ }^{1,6}$ The inclusion of a drug in the liquid phase means that ES can be employed to generate solid dispersions (SDs) of drug-in-polymer. ${ }^{1}$ The very rapid nature of the drying process $\left(10^{-2} \mathrm{~s}\right.$, approximately) means that these tend to be amorphous in nature (amorphous solid dispersions, ASDs) and thus can accelerate dissolution rates and improve apparent solubility. ${ }^{1}$ This is of great interest to the pharmaceutical industry, as increasing numbers $(>75 \%)$ of emerging drug candidates fall in Biopharmaceutical Classification System Classes II and IV, and hence suffer from poor solubility.

There exist a range of other routes to preparing SDs and ASDs, with the most commonly applied being hot melt extrusion (HME), spray drying, and freeze drying. ${ }^{10-13}$ All these technologies have great utility in the pharmaceutical industry, and there are marketed products fabricated using all three. However, all have fundamental disadvantages associated with them. HME and spray drying apply heat, and thus are not

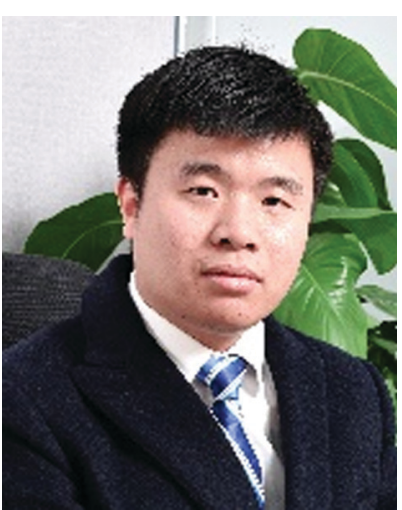

Jinglei Wu
Jinglei Wu received his $P h D$ in Biomedical Engineering from the University of Texas at Arlington and Southwestern Medical Center joint program in 2017. He then worked as a scientist in the biotech company Progenitec Inc., before joining the Department of Bioengineering at Donghua University as a lecturer in 2018. His research interests focus on naturally-derived materials for tissue engineering and regenerative medicine applications.

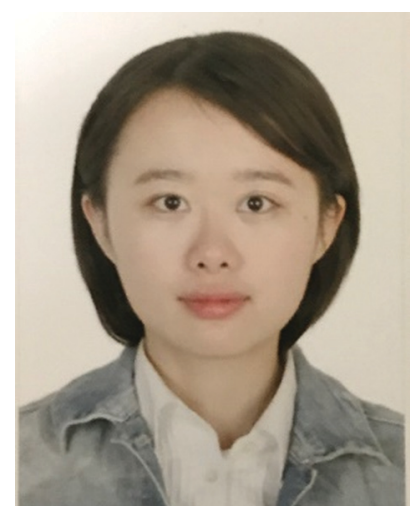

Ziwei Zhang
Ziwei received her $B S$ degree (2012) in pharmaceutical science and MS degree (2014) in pharmaceutical analysis from Peking University. She then obtained an MSc degree in drug discovery and development at UCL in 2017. She is now a third year PhD student at the UCL School of Pharmacy working in Gareth's group. Her research interests focus on hybrids of inorganic and polymer materials for MRI-based theranostics.

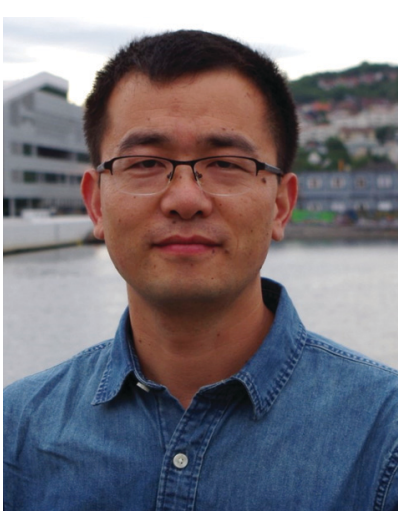

Fenglei Zhou
Fenglei is a senior research fellow at UCL, working in the Centre for Medical Image Computing and UCL School of Pharmacy. Fenglei obtained his BSc and MSc from Qingdao University (China) and his PhD from the University of Manchester. From 2010 to 2019, Fenglei worked as a research associate and then a research fellow in the Manchester Centre for Imaging Sciences. He has general research interests in electrohydrodynamics and polymer materials. In the past ten years, Fenglei has participated in projects funded by the EU, EPSRC and CRUK, in which he pioneered the development of tissue-mimicking phantoms for diffusion MRI. These phantoms have won recognition in the MR community and have been used in ten world-leading university research groups.

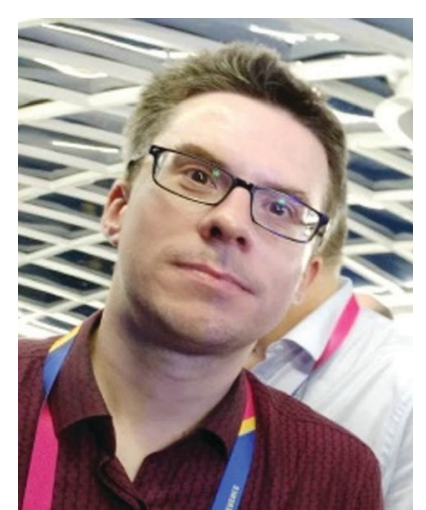

Gareth R. Williams
Gareth is Professor of Pharmaceutical Materials Science and Head of Pharmaceutics in the UCL School of Pharmacy. He was educated at the University of oxford, and then worked in science programme management and as a post-doctoral researcher before obtaining his first independent academic appointment at London Metropolitan University in 2010. He moved to UCL in 2012 as a lecturer, and was promoted to associate professor in 2016 and full professor in 2020. Gareth's research interests focus on the use of inorganic and polymer-based nanomaterials in biomedicine, as well as in the development of advanced analytical techniques. 


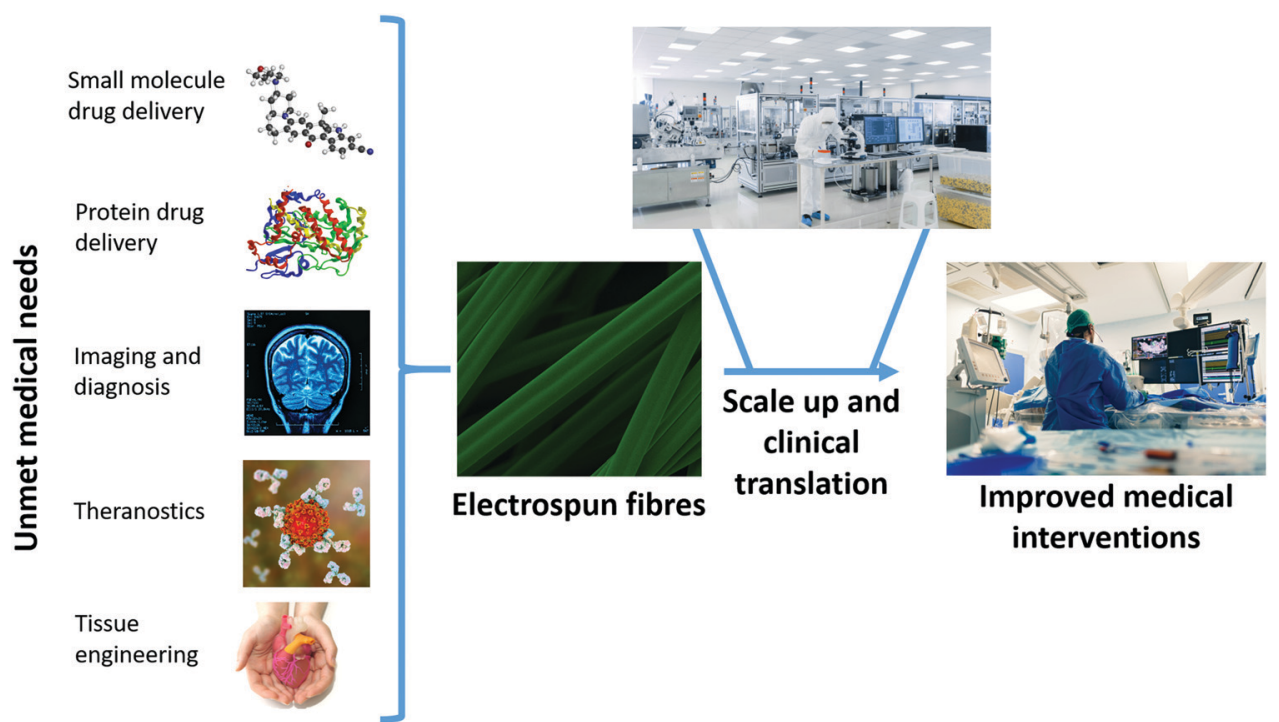

Fig. 1 A schematic illustration of the major applications of electrospinning in biomedicine.

for the development of clinical products. The range of biomedical applications to which ES can be applied is summarised in Fig. 1.

\section{The electrospinning process}

In the most commonly used electrospinning process, a solution of a polymer and drug is prepared in a volatile solvent. This is then loaded into a syringe fitted with a metal needle (the "spinneret"), and ejected at a controlled rate using a syringe pump. Without the application of an electrical field, droplets will form as a result of surface tension forces. In ES, the positive electrode of a high-voltage power supply is attached to the needle, with the grounded electrode connected to a collector plate. The application of voltage causes a charge to build up on the ejected droplet, which deforms into a conical shape (the "Taylor cone"). Above a critical voltage, a polymer jet is ejected from the Taylor cone and accelerates towards the grounded collector. As it does so, the jet narrows and solvent is evaporated. This ultimately results in nano-microscale dry fibres being deposited on the collector, if the processing parameters are appropriately established. A schematic of the ES process is depicted in Fig. 2.

The precise details of the electrospinning process fall outside the scope of this paper, and the interested reader is directed elsewhere for a fuller explanation. ${ }^{4,14,15}$ For a successful process, the solution, processing and environmental parameters must all be considered. The solution needs to have a suitable viscosity to allow entanglement between polymer chains, such that the Taylor cone can be deformed into a polymer jet and yield dry fibres (a lower viscosity will result in a sister process termed "electrospraying", and particulate products). Conductivity and volatility are also important solution parameters to consider. The processing parameters include the applied voltage, the dispensing rate, and the distance between the spinneret and the

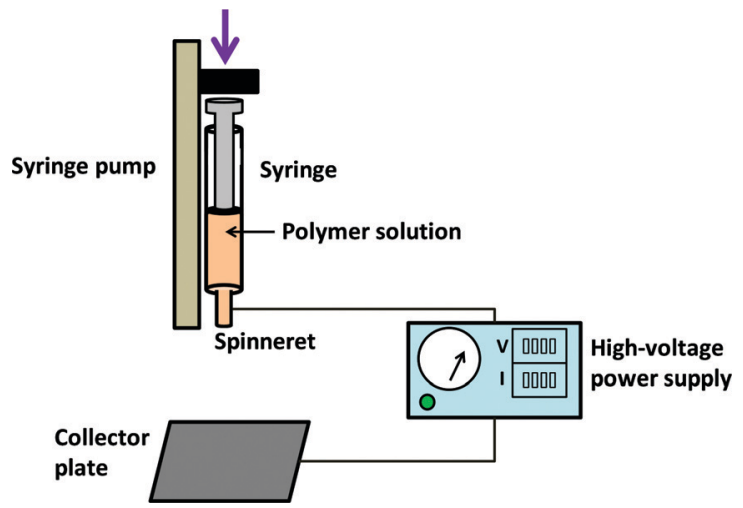

Fig. 2 A schematic illustration of the electrospinning process.

collector. Environmental parameters comprise the temperature and relative humidity.

Perhaps the most important part of the ES apparatus is the spinneret. The rapid nature of the process means that the architecture of the spinneret is, if the experiment is properly optimised, propagated into the products. In the simplest embodiment of ES (monoaxial spinning), a single solution of drug and polymer is dispensed through a single needle to give monolithic fibres (which have the same composition throughout). However, it is possible to work with two or more solutions to yield more complex architectures (e.g. core/shell fibres). Emulsions and suspensions can also be processed by ES, with the former typically resulting in core/shell materials.

\section{Scope}

This perspective will explore the key developments in the use of ES to develop pharmaceutical formulations, diagnostic and theranostic materials, and in tissue engineering. It will not 
seek to review the literature in detail, but rather will consider selected examples to illustrate the most fundamental points. We will begin by considering monoaxial ES for the delivery of small molecule drugs, before moving on to discuss multi-fluid ES and the use of ES in formulating proteins. This will be followed by consideration of the potential of the ES process in diagnosis, imaging, for theranostic applications, and in tissue engineering. The paper will finish by discussing scale up and GMP (Good Manufacturing Practice) considerations, and the potential for translation to the clinic.

\section{Monoaxial electrospinning of small molecule drugs}

One of the major areas in which ES has been explored is in the development of drug delivery systems (DDSs), seeking to overcome some of the inherently problematic properties of drug molecules or to target release to a particular part of the body. Monoaxial electrospinning has great advantages in terms of the simplicity of the fabrication process. The resultant fibres (Fig. 3a) have large surface areas, and typically contain an amorphous dispersion of drug molecules. This renders them inherently suitable for developing fast-dissolving drug-delivery systems and for overcoming the solubility issues encountered with many active pharmaceutical ingredients (APIs). To generate such formulations, a hydrophilic polymer such as poly(vinyl pyrrolidone) (PVP) is employed. These dissolve rapidly in aqueous media, and therefore can lead to very rapid drug release. This has been shown on many occasions and with a range of APIs (e.g. ibuprofen, ${ }^{16}$ irbesartan, ${ }^{17}$ vitamin $\mathrm{B},{ }^{18}$ and ketoprofen ${ }^{19}$ ). In one such study, Illangakoon et al. prepared PVP fibres loaded with paracetamol and caffeine. ${ }^{20}$ These were found to disintegrate fully in $<300 \mathrm{~ms}$ in conditions mimicking the oral cavity (see Fig. 3b), giving them great potential to provide rapid relief of symptoms or to treat patients who have difficulty swallowing (such as the paediatric and geriatric populations). ${ }^{21}$

To a large extent, drug release from ES fibres is controlled by the properties of the polymer carrier. Thus, while hydrophilic polymers give accelerated drug release, the use of a slowly dissolving or degrading polymer, or one which is insoluble, will result in extended drug release over hours to weeks. Blends of polymers can be processed by ES, allowing for extensive
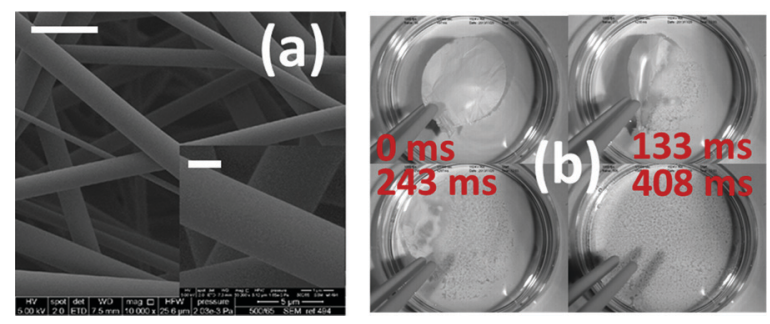

Fig. 3 (a) Scanning electron microscope images of PVP fibres loaded with paracetamol $(21.87 \% \mathrm{w} / \mathrm{w})$ and caffeine $(2.89 \% \mathrm{w} / \mathrm{w})$ [scale bars: main image $5 \mu \mathrm{m}$; inset $1 \mu \mathrm{m}]$; (b) high-speed digital camera images recorded at different after the addition of these fibres to simulated saliva. Adapted with permission from ref. 20 (Illangakoon et al., 2014). Copyright Elsevier 2014. control over the precise drug release profile obtained. Further, multiple drugs can be incorporated into a single fibre for improved therapeutic outcomes, or additional components (e.g. a sweetener to enhance taste, or a permeation enhancer $)^{20}$ may be added to enhance patient compliance or functional performance. There are many examples of extended release DDSs based on ES fibres. ${ }^{14,15}$ Cancer treatments have attracted a lot of attention here. For instance, poly(lactide-co-glycolide) (PLGA) fibres loaded with the anticancer drug paclitaxel resulted in release sustained for more than 60 days and could be used to effectively treat glioma tumours. $^{22}$ In other work, dacarbazine-loaded fibres were explored as an implant for the treatment of brain tumours and found to be effective in vitro, ${ }^{23}$ and disulfiram-loaded fibres were shown to be potent against lung cancer cells in vitro. ${ }^{24}$ Several recent reviews discuss the applications of electrospinning in cancer therapy in more detail. ${ }^{25,26}$ There also exist a myriad of other applications of extended release materials: to give just one example, mucoadhesive fibres can be employed to give sustained release in the oral cavity. ${ }^{27}$

Fibres which respond to external stimuli such as $\mathrm{pH}$ or temperature may be employed to target drug release. The Eudragit family of polymers (L100-55, L100, S100) has been widely explored for delayed-release oral formulations prepared by ES. These polymers are methacrylate systems which are insoluble below a certain $\mathrm{pH}$ (5.5, 6.0 and 7.0 respectively) but freely soluble at higher $\mathrm{pH}$. Fibres prepared from these polymers can effectively prevent drug release in the acid $\mathrm{pH}$ of the stomach, but will dissolve upon exiting the stomach and reaching the approximately neutral $\mathrm{pH}$ conditions of the small intestine. Thus, API release can be targeted to the small intestine, which can be beneficial for avoiding gastric irritation and enhancing absorption. This concept has been proven by Shen et al. for the non-steroidal anti-inflammatory (NSAID) drug ketoprofen ${ }^{28}$ and by Illangakoon and co-workers for the antispasmodic API mebeverine hydrochloride, ${ }^{29}$ among other studies. $^{30,31} \mathrm{pH}$-sensitivity can also be imparted through the inclusion of a third component into the recipe: the incorporation of sodium bicarbonate has been shown to accelerate drug release in acidic conditions, giving fibres which could be used to target API release to the tumour microenvironment. ${ }^{32}$ Thermo-responsive polymers can be included in the ES process, leading to fibres which can respond to temperature. The latter could be used to trigger drug release, ${ }^{33}$ or in a wound dressing to reduce secondary injuries caused by changing dressings. ${ }^{34}$ By selecting a suitable blend of polymers, fibres which are both $\mathrm{pH}$ and temperature sensitive can be fabricated. ${ }^{35}$

The simple monoaxial electrospinning process is thus very powerful, and can generate formulations with a wide range of applications in drug delivery. There is one significant drawback though, which arises from the monolithic nature of the fibres. The drug cargo is spread evenly throughout the polymer filament, and since the surface area-to-volume ratio of the fibres is very high this results in a significant proportion of the drug being present at the fibre surface. When the fibres come into contact with aqueous media, there hence tends to be a "burst" of API release, as drug molecules at the surface can interact with the water and dissolve, even if the polymer carrier is not soluble. The extent to which this happens depends on the 
solubility of the drug. This burst release is not a concern in the case of fast-dissolving formulations, but it can diminish the performance of systems designed for extended or delayed release. To overcome this issue, multi-fluid ES can be applied.

\section{Multi-fluid electrospinning of small molecule drugs}

Multi-fluid ES involves the processing of multiple fluids at the same time. Because the structure of the spinneret is propagated into the fibre product, it permits the production of fibres with a range of architectures, and can be used to prepare formulations with variable and tuneable API release profiles (Fig. 4). ${ }^{36}$ It also significantly broadens the range of polymer solutions that can be processed by ES. In monoaxial spinning the polymer solution requires appropriate properties (e.g. viscosity) to be converted into fibres. If these properties are not suitable for ES (e.g. viscosity too low), then no fibres can be prepared. In contrast, in the multi-fluid experiment, it is possible to process solutions whose properties do not allow them to be individually electrospun ("unspinnable" fluids): so long as at least one of the fluids in the experiment is independently spinnable, it is generally possible to generate a fibre product. Thus, a solution with low viscosity can be converted into a solid fibre product in coaxial ES so long as the companion solution is electrospinnable.

While in theory any number of fluids can be processed, at present the state of the art is limited to two or three fluids, with a few reports of four-fluid ES. ${ }^{37}$ With two solutions, the needles can be arranged concentrically (one nested inside another, or coaxial spinning), giving core/shell products. ${ }^{38}$ Aliter, the two fluids could be dispensed in a side-by-side configuration, resulting in Janus fibres (with two different sides). A threelayer concentric spinneret can be used to prepare triaxial fibres, or alternatively more complex needle arrangements can be implemented to generate for instance core/shell fibres with a Janus core.

The apparatus required for multi-fluid ES is essentially the same as the monoaxial apparatus displayed in Fig. 2, except

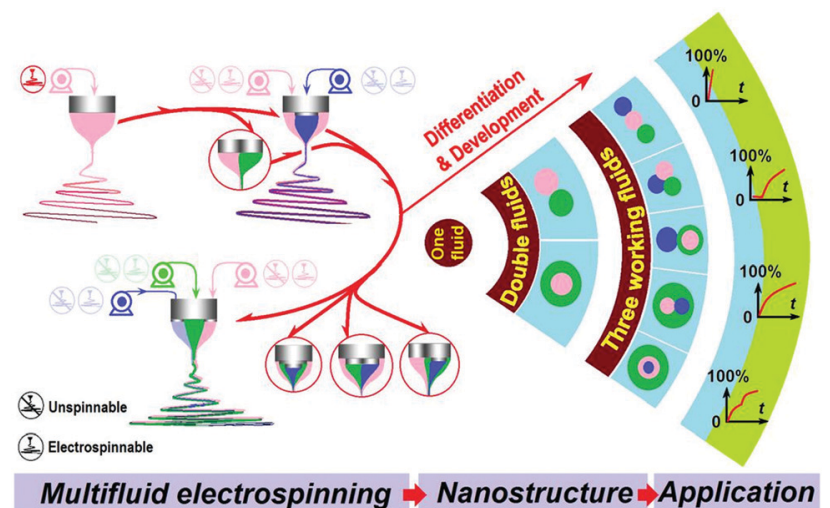

Fig. 4 A schematic diagram showing the possible arrangements of liquids in multi-fluid ES, the nanostructures which can be produced as a result, and the potential drug release profiles. that multiple syringe pumps are typically required (one to drive each working fluid) and the spinneret architecture is more complex. The properties of the working fluids and operational parameters need more careful consideration for multi-fluid ES, however. $^{39}$ The volatility and drying rates of the different solutions is important, as are the relative flow rates.

The multiple-compartment structures produced by multi-fluid ES have several benefits for developing novel DDSs. The components, compositions, and the spatial distribution of APIs within the materials can be tailored to yield sophisticated drug release profiles (e.g. immediate release, delayed release, sustained release and multiple-phase release; see Fig. 4). The core/shell structures of fibres from coaxial electrospinning have been widely used to prevent the initial burst release commonly experienced with monolithic materials produced from monoaxial spinning. This is achieved using a simple polymer solution as the shell, while the core comprises a drug/polymer blend solution. The resultant fibres thus have a blank polymer shell, and there is no contact between the release medium and the API-loaded compartment on first immersion. The drug release rate is controlled by the speed at which the shell compartment dissolves or degrades, or by the rate of drug diffusion through the shell. This approach has been demonstrated in a number of studies, for instance that of $\mathrm{He}$ et al. where core/shell fibres of poly(lactide) (PLA) were prepared with the antibiotic tetracycline hydrochloride confined to the core. ${ }^{14,40}$

Core/shell fibres have also been used to provide delayed release to avoid release in the stomach and target the drug to the small intestine (using a $\mathrm{pH}$-sensitive polymer shell). ${ }^{41,42}$ Multifunctional materials can be prepared, with different APIs in the core and shell compartments ${ }^{43}$ or with flavour enhancers or surfactants added to the shell to improve palatability or permeation of the drug through biomembranes. ${ }^{44,45}$ The latter might be expected to be more effective than including the flavor enhancer in a monolithic fibre, because the shell of a core/shell formulation will dissolve before the core, and hence the flavor enhancer is freed into the mouth before the unpleasant tasting drug. Triaxial systems have been less explored owing to the complexity of fabrication, but there are a number of studies in the literature exploring these. ${ }^{46,47}$ The increased control over the fibre architecture which results can yield highly desirable APIs release profiles. For instance, Yu et al. reported triaxial ethyl cellulose/ketoprofen fibres with varied concentrations of API in the three fibre compartments, and showed that zero-order release could be obtained (Fig. 5). ${ }^{48}$ This is highly sought after in pharmaceutical science, but very challenging to achieve. Alternatively, using a hydrophilic exterior polymer with a hydrophobic middle layer has been found to allow the fibres to interact favourably with cells while still releasing a drug cargo over a prolonged period of time. ${ }^{49}$

There is also relatively little work in the literature looking at Janus fibres for pharmaceutical applications, but there are potential benefits of these over the more widely explored core/ shell structures. With Janus fibres, the two sides are both in contact with the release milieu, which could be advantageous to, for instance, release two different drugs in the same location but at different rates, or to tune API release profiles. ${ }^{50}$ 


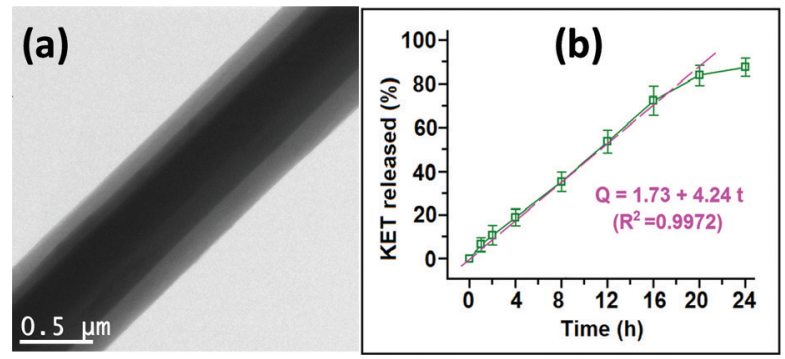

Fig. 5 The triaxial fibres prepared by Yu et al. (a) Transmission electron microscopy image, and (b) the resultant zero-order drug release profile. Adapted with permission from ref. 48 (Yu et al., 2015). Copyright 2015 American Chemical Society.

The complex nanostructures which can be prepared by multi-fluid ES are still in the very early stages of exploration, and there are extensive possibilities for future developments. ${ }^{51}$ The diversity of materials which can be produced, in combination with the ability to process unspinnable liquids, means that a wide range of multifunctional formulations are expected to emerge in the coming years.

\section{Electrospinning and proteins}

Protein-loaded biomaterials are generating considerable interest due to the growing importance of immunotherapy and tissue engineering in modern medicine. ${ }^{52,53}$ The complex and fragile structures of many therapeutic proteins require advanced delivery methods and careful optimisation of formulation and manufacturing conditions. ${ }^{54}$ ES offers a simple solution for the fabrication of protein-loaded materials. Multiple approaches have been proposed for the incorporation of therapeutic proteins in electrospun scaffolds. These can be broadly divided into post-fabrication surface functionalisation, emulsion ES, and coaxial ES.

Physical adsorption is often used to attach proteins to polymeric surfaces. This simple approach does not require multi-step treatments in harsh conditions and relies solely on relatively weak electrostatic, van der Waals and hydrophobic interactions. ${ }^{55}$ The 3D-structure of ES fibres provides a large surface area for protein adsorption. The immediate release of bioactive agents which results from weak adsorption to the surface is desired for certain applications where instant biological action is needed. For example, Xia and $\mathrm{Lv}^{56}$ described the dual delivery of growth factors for peripheral nerve regeneration using PLA nanofibres. Recombinant human nerve growth factor (NGF) was loaded into the core of the fibre, and the surface functionalised with human vascular endothelial growth factor (VEGF) by physical adsorption. The resultant material was able to effectively support nerve regeneration in rats in vivo.

Chemical conjugation of bioactive molecules onto the fibre surface via rigid covalent bonding can immobilize them on the surface for an extended period of time. There are a range of routes to such functionalisation, for instance using polydopamine chemistry. ${ }^{57,58}$ In a 2019 study, Liu et al. ${ }^{59}$ applied this method to conjugate osteogenic growth peptide to PLA nanofibres, which led to improved cell adhesion and proliferation (Fig. 6).

While monoaxial ES can be employed to generate fibres on which proteins are subsequently attached, it is generally not suitable for preparing fibres with the protein incorporated inside the structure. This is because it uses volatile organic solvents, which tend to cause damage to the protein structure and diminish therapeutic efficacy. This can be avoided using emulsion or multi-fluid ES. In the former process, a core-shell nanofibre structure is formed by ES of an emulsion formed from an aqueous phase (containing protein) and an organic phase (polymer). ${ }^{60}$ This is a simple approach, but the proteinpolymer blend must be carefully optimized to ensure no loss of bioactivity resulting from accidental exposure of biomolecule to the organic solvent. A non-ionic surfactant is often incorporated in the formulation to reduce the contact of the protein with organic solvents. ${ }^{61}$ Frizzell et al. used surfactant-assisted emulsion ES to generate enzyme-loaded electrospun Eudragit fibres intended for oral delivery. ${ }^{62}$ These could prevent protein release in the $\mathrm{pH}$ conditions of the stomach, thereby avoiding the risk of enzyme degradation and targeting release to the small intestine.

In coaxial ES, the two working fluids are physically separated until they exit the spinneret, and hence this approach too can minimise protein exposure to organic solvent. The resulting fibre usually holds the protein in the core, with the polymer shell controlling the release rate of the cargo. Angkawinitwong et al. have exploited this method for the fabrication of bevacizumab-loaded poly( $\varepsilon$-caprolactone) (PCL) fibres for the treatment of age-related vascular macular degeneration in the
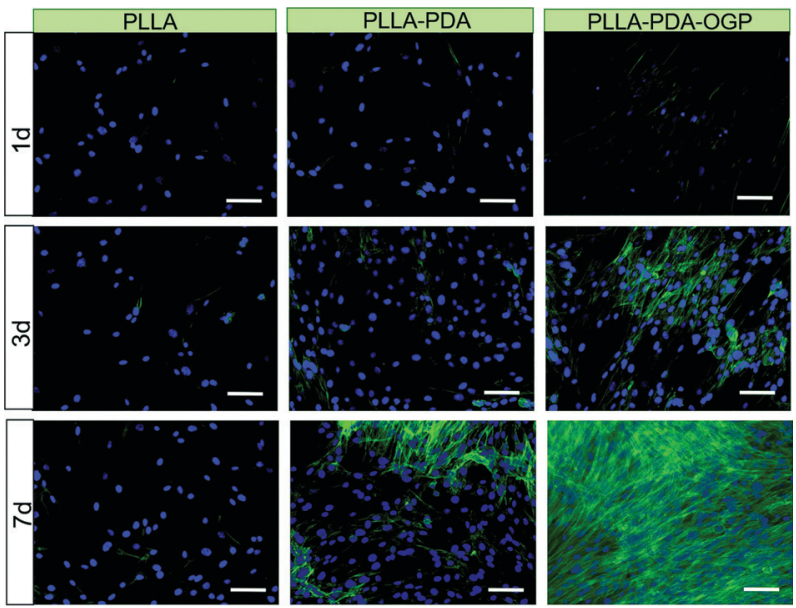

Fig. 6 The use of polydopamine chemistry to facilitate cell growth on ES fibres. Scale bar: $100 \mu \mathrm{m}$. Fibres were prepared from pol(L-lactide) (PLLA), and then immersed in polydopamine to yield PLLA-PDA fibres. These were further immersed in a solution of the osteogenic growth peptide (OGP) to conjugate the peptide and generate PLLA-PDA-OGP. Cell nuclei are blue and the intracellular protein $\mathrm{F}$-actin is green. The presence of OGP on the fibre surface clearly encourages cell growth. Reproduced from ref. 59 (Liu et al., 2019) under the terms of the Creative Commons CC BY 3.0 license. Published by The Royal Society of Chemistry. 
eyes. ${ }^{63}$ It was found that the charge of the protein during ES had a major impact on its integrity and release rate; by formulating at the isoelectric point (the $\mathrm{pH}$ at which the protein has no net charges) protein degradation could be avoided and the release period extended.

Protein-loaded ES fibres therefore seem to have significant clinical potential. For this to be truly realised, future studies need to consider protein stability and bioactivity in more detail, and use therapeutic biomolecules rather than model proteins. ${ }^{64,65}$ With the constantly growing interest in protein therapeutics, it is anticipated that the next decade will bring more insight into the intricacies of electrospinning as a formulation route for biologic APIs. Beyond proteins, it has been shown that cells can also be processed by ES without loss of activity. ${ }^{66-68}$

\section{Diagnosis and imaging}

In addition to their use in therapy, materials from ES also have great potential in diagnosis and imaging. In one embodiment, this can be achieved by preparing electrospun fibres loaded with an imaging agent in place of a therapeutic API. In one example of this, Jin et al. prepared core/shell fibres with a Eudragit S100 shell and a core containing poly(ethylene oxide) (PEO) and the magnetic resonance imaging (MRI) contrast agent gadolinium(III) diethylenetriaminepentaacetate hydrate (Gd(DTPA)). ${ }^{41}$ The fibres could preclude the release of Gd(DTPA) in acidic environments, but were soluble at neutral pHs. It was thus proposed that they could be used in colon MRI applications.

Beyond this, there are other opportunities for ES fibres in diagnosis. The high surface area of the fibres lends them to applications in the sensing of biomarkers, for instance for cancer. ${ }^{69}$ ES materials have been explored to detect diagnostic gases in the breath, or to quantify circulating molecules in the blood. Typically, to generate a sensor a metal salt or metal nanoparticle (NP) is incorporated into polymer-based fibres via ES. These are then calcined to generate metal salt-based fibres with high surface areas. For instance, Kim et al. prepared fibres by electrospinning a solution of platinum chloride, tungsten ethoxide and poly(methyl methacrylate), and calcined the product to give $\mathrm{Pd}-\mathrm{WO}_{3}$ fibres. These fibres could be used to detect hydrogen sulfide and toluene (as biomarkers for halitosis and lung cancer) via the changes in resistivity which occurred upon their exposure to these gases. ${ }^{70}$

Part of the attraction of MRI is its ability to provide noninvasive quantitative measurements relating to the tissue microstructure, ranging from measurements of axonal packing in the brain to tumour cell sizes. To be able to use these capabilities clinically, validation is required. Synthetic tissues, with known microstructural properties, offer one approach to providing such validation. Hollow polymer nano/microstructures with cylindrical geometries can be used as suitable synthetic tissues, and can be prepared via coaxial ES. Given the close match between the structures of the products of ES and the human extracellular matrix and fibrous tissue, ES has attracted considerable attention for the generation of reproducible validation materials. Coaxial ES has been used to prepare hollow fibres from a number of polymers (e.g. with a PCL shell and PEO core). This can be done in a single step, or by preparing a core/shell fibre with a soluble core and then dissolving the latter. $^{71-73}$ The size and morphology of the fibres are closely affected by the core/shell solution properties (e.g. solvent and concentration) and process parameters (e.g. solution flow rate, electric field), and optimisation is required to produce highquality hollow materials (see Fig. 7a). ${ }^{38,74}$

Precise deposition of the fibres in a desired location or specific pattern is required to prepare high-quality tissue mimics for MRI. This can be achieved by direct-writing (or near-field) $\mathrm{ES}^{75}$ in which the spinneret-collector distance is reduced to a few millimetres. Combining this set-up with a motor-controlled $\mathrm{X}-\mathrm{Y}$ stage collector ${ }^{75}$ and/or using a rotating collector ${ }^{77}$ allows position-controlled deposition of patterned fibres, as shown in Fig. $7 \mathrm{~b}-\mathrm{d} .^{76}$ Extensive control can be exercised over the patterns deposited (see Fig. 7c and d) ${ }^{78,79}$ which enables ES "phantoms" mimicking native tissues such as the white matter in the brain ${ }^{80}$ or myocardial tissue (heart muscle) to be produced. This is depicted in Fig. 8. For instance, Teh et al. prepared cardiac phantoms from coaxial ES fibres wound at different helix angles. ${ }^{81}$ The MRI data acquired from this phantom were found to be physiologically relevant, and the phantom remained stable over a testing period of 4 months. Such phantoms are increasingly sought after to enable calibration of clinical MRI scanners. ${ }^{82}$

\section{Theranostic formulations}

Theranostics refers to the combination of diagnostic imaging and therapy in a single formulation. In contrast to conventional treatment, which uses separate systems for these two goals,
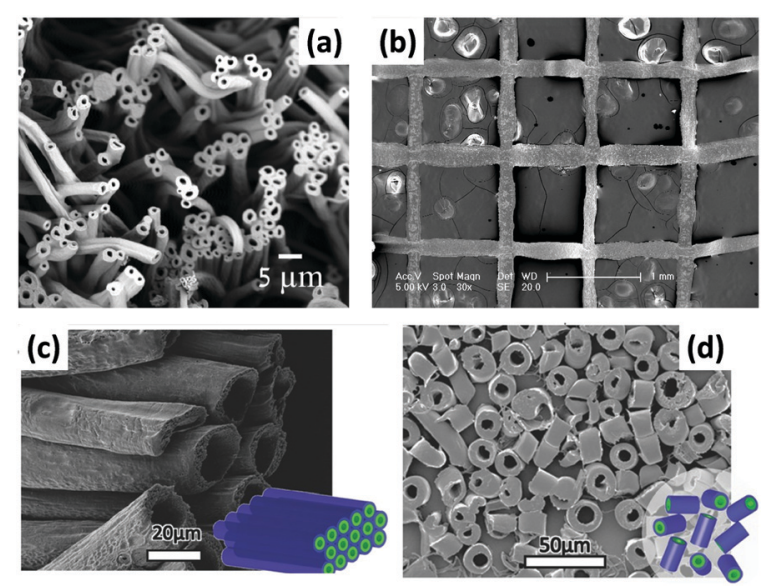

Fig. 7 (a) An SEM image of hollow polyvinylidene fluoride-hexafluoropropylene ES fibres; ${ }^{73}$ (b) near-field coaxial ES of patterned sugar-PCL core/sheath fibres using a moving $\mathrm{X}-\mathrm{Y}$ stage ${ }^{75}$ ( $c$ and $\mathrm{d}$ ) far-field coaxial ES of fibres comprising a PLA shell and hyaluronic acid core, showing the different patterns which can be established with a rotating collector. ${ }^{76}$ Reproduced with permission from (a) ref. 73 (Halaui et al. 2011; copyright Elsevier); (b) ref. 75 (Zhou et al. 2011, copyright Elsevier); (c and d) ref. 76 (Sitt et al. 2016, copyright Wiley). 
theranostics can offer real-time time information on diseased areas, allowing an API to be precisely delivered to the target site with real-time monitoring of therapeutic progression possible. ${ }^{85,86}$ A number of platforms, including inorganic, polymer and biological systems, have been used to develop theranostics. ${ }^{86,87}$ However, the synthetic process required is often complicated and timeconsuming. Such sophisticated systems are also difficult to produce on a large scale. ES has hence begin to attract attention for theranostic applications, owing to its simplicity combined with the ability to incorporate a wide range of functional components into a single fibre. ${ }^{14,41}$

In one example, electrospun PCL/gelatin fibres loaded with iron oxide and Ag nanoparticles (NPs) were founded to enhance contrast in MRI (via the iron oxide NPs) and exert anti-bacterial activity (via the Ag NPs), while also being highly biocompatible. ${ }^{88}$ In other work, $\mathrm{Fe}^{2+}$ doped calcium phosphate NPs were encapsulated into electrospun fibres with the chemotherapeutic API temozolomide. The presence of the NPs led to enhanced MRI contrast, and after implantation in vivo the fibres gave sustained drug release for up to one month. ${ }^{89}$ This permitted simultaneous monitoring of potential side effects for up to 3 months. ${ }^{89}$ Singh et al. developed theranostic wound-dressing fibres comprising polyurethane, a ciprofloxacin-based prodrug and a chromogenic probe (Fig. 9). ${ }^{90}$ The latter changes colour in the presence of lipase, an extracellular enzyme secreted by certain pathogenic bacteria. The presence of lipase additionally triggered the release of ciprofloxacin from the fibres. Hence, the presence of pathogenic bacteria in the wound site can be both visualised and treated simultaneously, helping to avoid overuse of antibiotics (Fig. 9).

Core/shell fibre systems from coaxial ES have also been investigated for simultaneous MRI and drug delivery for irritable bowel syndrome or colon cancer. A theranostic platform comprising a pH-responsive shell and PEO core loaded with indomethacin and Gd(DTPA) was developed. ${ }^{91}$ The $\mathrm{pH}$-responsive shell allows the API to be targeted to the colon, where the PEO core will adhere to the walls of the intestine and swell ensuring sustained release of the API and Gd(DTPA). Such co-delivery of therapeutic and diagnostic components makes it possible to monitor disease progression during treatment, hence improve the drug efficacy and reducing off-target effects. ${ }^{91}$ This work was recently built upon by Zhang et al., who prepared Eudragit fibres loaded with an anticancer

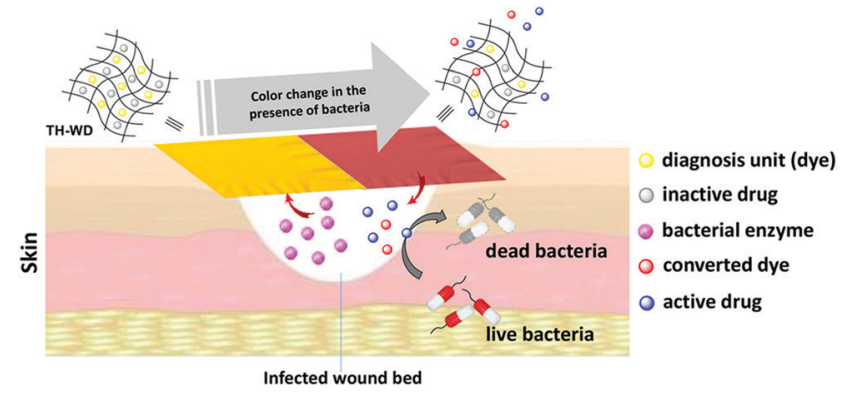

Fig. 9 The theranostic wound-healing platform developed by Singh et al. ${ }^{90}$ Fibres were prepared loaded with a dye and antibiotic product. The presence of the enzyme lipase, secreted by pathogenic bacteria, caused the dye to change colour and also led to the release of the antibiotic. Reprinted with permission from ref. 90 (Singh et al., 2019). Copyright 2019 American Chemical Society.

drug and Fe oxide nanoparticles. ${ }^{92}$ It was shown that there was a direct correlation between the extent of drug release and the MRI signal, which could potentially allow for indirect monitoring of drug release.

\section{Tissue engineering}

ES nanofibres provide cells with a beneficial microenvironment that resembles the native extracellular matrix. This has motivated researchers to explore ES scaffolds for a variety of tissue engineering applications. ${ }^{93-95}$ Many synthetic and natural materials have been processed into fibrous scaffolds via ES, and also loaded with bioactive molecules to modulate/promote tissue regeneration. Often, the scaffolds are designed to be "bioresorbable", meaning that they act as a template which is, over time, recapitulated by the cells of the host while the fibres slowly degrade and are excreted.

Clinically, there is a significant unmet need for off-the-shelf tubular grafts, and ES has been proven to be a versatile technique to prepare nanofibrous scaffolds for such grafts. Small diameter vascular grafts $(<6 \mathrm{~mm})$ for the bypass or replacement of diseased or damaged blood vessels can be obtained by using a suitably sized rotating drum as the collector in ES. The resultant scaffold allows good mechanical matching and structural similarity between the graft and the native vessels. ${ }^{96}$ To mimic the distinct layer structures of native vessels

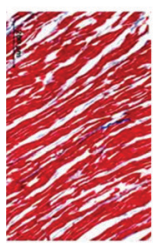

(a)

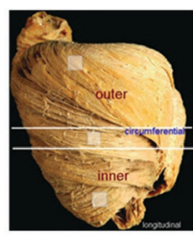

(b)

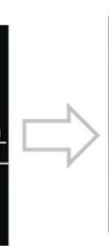

(c)

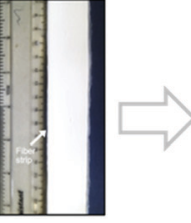

c)

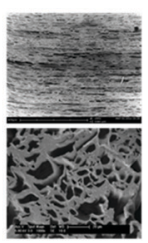

(d)

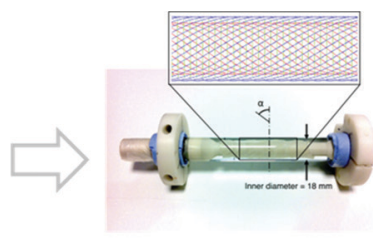

(e)

Fig. 8 A schematic showing the development of a cardiac phantom by coaxial ES. (a) Longitudinal section of the native myocardium (reprinted with permission from ref. 83, Wang et al. 2012; copyright Springer Nature); (b) the progression of the helical angle present in the dissection of a porcine heart (reprinted with permission from ref. 84, Partridge et al. 2014, copyright BMJ Publishing Group); (c) a coaxial ES hollow microfibre strip; (d) SEM micrographs showing fibre orientation and cross-sections in the coaxial ES fibre strip; (e) a prototype of a cardiac phantom. (c-e) are reproduced from ref. 81 (Teh et al., 2016, an open access journal published under a CC license). 
as closely as possible, electrospun grafts with multiple layers have been generated. Surface functionalization can also be applied to prevent blood clots forming and aid remodeling of vascular grafts. ${ }^{97}$ Many studies have reported successful regeneration of blood vessels in animal models, but ES vascular grafts for humans are not yet available.

ES tubular scaffolds have also shown potential in peripheral nerve regeneration, but it remains challenging to achieve desired physiological functions such as the transmission of electrical stimuli (since the polymers used for ES are generally not electrically conductive). The inclusion of conductive polymers is one route to potentially circumvent this problem, but can also compromise biological performance. As an alternative, a conductive nerve conduit was prepared by in situ redox reactions of graphene oxide on the surface of ES scaffolds. ${ }^{98}$ These exhibited promising mechanical properties and electroactivity, induced nerve cell differentiation, and guided peripheral nerve regeneration to a comparable level as current gold standard autografts in a rodent model. The incorporation of drugs into the fibres to stimulate nerve growth has also been shown to be beneficial. ${ }^{99}$

In general, fibre scaffolds produced by ES contain relatively densely packed fibres, and it can be difficult for cells to penetrate into the matrix, therefore preventing the complete regeneration of the desired tissue. A novel ES technique was recently introduced to convert the as-spun nanofibres into individual short fibres that can be reconstructed to highly porous and elastic aerogels. ${ }^{100}$ This technique essentially involves the homogenization of the fibre mat produced by ES, and increases the capacity of ES nanofibres in tissue engineering because the resultant porous scaffolds support cell infiltration and proliferation, which drives robust tissue remodeling and regeneration. For instance, ES aerogel scaffolds induced osteogenic differentiation of mesenchymal stem cells and promoted cranial bone regeneration in a rat model. ${ }^{101,102}$ They have also been shown to enhance cartilage repair in a rabbit model. ${ }^{103}$ The aerogels can be crafted into a range of 3D shapes suitable for use in different tissue engineering applications. ${ }^{104}$ It is also possible to directly combine $3 \mathrm{D}$ printing and electrospinning to generate 3D structures. ${ }^{93,104,105}$ The interested reader is directed to two recent reviews for more information. ${ }^{93,104}$

While ES scaffolds with porous structures can be desirable, scaffolds with densely packed fibres are also beneficial in some scenarios because they effectively resist cell infiltration and tissue ingrowth. ES PCL/gelatin membranes have for instance been used as a physical barrier to prevent cardiac operative adhesions (a type of scar tissue arising after cardiac surgery) in a rabbit model. ${ }^{106}$ The incorporation of ibuprofen or siRNA into the fibres was also found to be beneficial here. ${ }^{107,108}$ In other work, MgO loaded ES fibres have been found to have significant promise in periodontal tissue regeneration. ${ }^{109}$

\section{Scale-up and clinical translation}

The above sections clearly indicate the great potential of electrospinning in a wide range of biomedical applications.
For ES fibres to achieve this potential, there is a need to move the experiment out of the lab and towards the clinic. In some cases, this involves the miniaturisation of equipment to allow it to be used at the point of care. To this end, there has been much recent work looking to develop portable ES apparatus for wound healing, with notable successes in this area. ${ }^{110}$ More commonly, the opposite is required: the low-throughput (ca. $0.5-20 \mathrm{~mL} \mathrm{~h}^{-1}$ ) benchtop electrospinning process needs to be scaled up to produce industrial quantities of materials. There are a number of approaches that can be used to achieve this, the simplest of which is to dispense fluid through multiple needles at the same time. ${ }^{111}$ However, since all the needles bear the same charge and are in close proximity, the electrical field around each needle interferes with its neighbours. ${ }^{112}$ Blocking of the needles can also be a challenge. A number of researchers have sought to overcome these issues. ${ }^{112,113}$ For instance, increasing the distance between the nozzles and the collector can compensate for instabilities in the electric field caused by adjacent needles. Using such multi-needle approaches, industrial scale amounts of material can be produced (e.g. Bioinicia's facilities can generate more than 2.2 million $\mathrm{m}^{2}$ of fibres per year). ${ }^{114}$

An alternative route to high-throughput is the needleless approach. This generates Taylor cones directly from the surface of a polymer solution (using a much higher potential difference than in a standard ES experiment), and these spontaneously arrange themselves in the most thermodynamically stable configuration possible. ${ }^{115}$ Commercial apparatus such as the NanoSpider ${ }^{\mathrm{TM}}$ equipment from Elmarco is available and can generate fibres at throughput of tens of millions of $\mathrm{m}^{2}$ per year. ${ }^{116}$ Working with a large exposed surface area of solvent carries its own hazards, given the volatility and flammability of many solvents used in ES, and to avoid this researchers have applied a number of modifications to permit

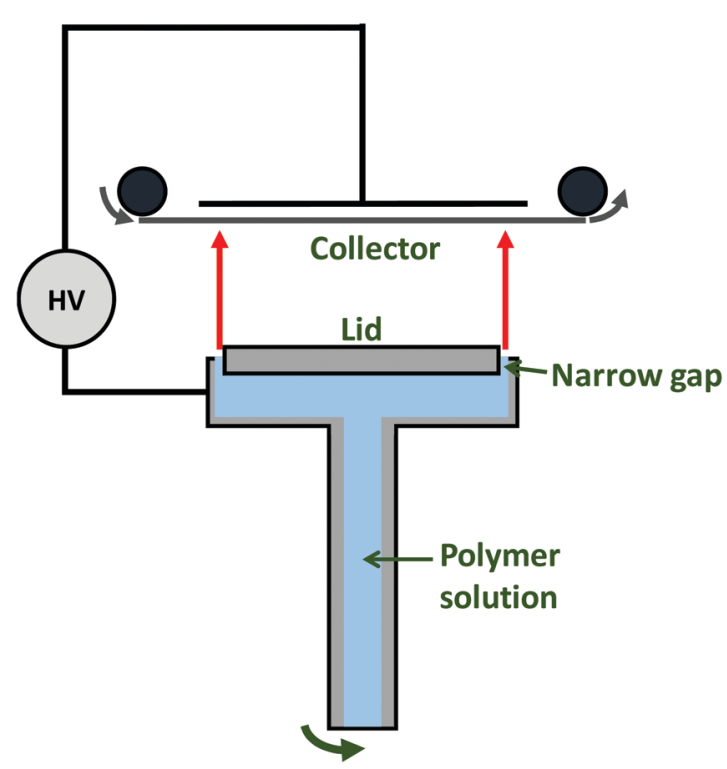

Fig. 10 Schematic diagram of the corona electrospinning apparatus developed by Molnar et al. ${ }^{117}$ 

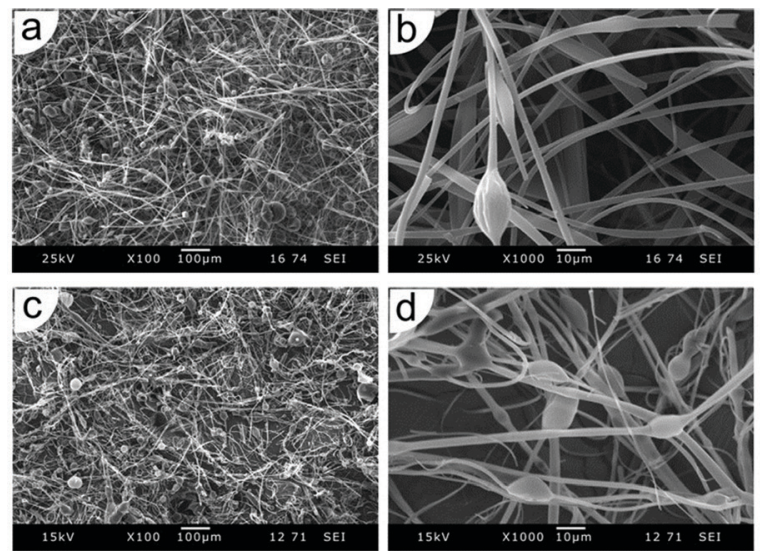

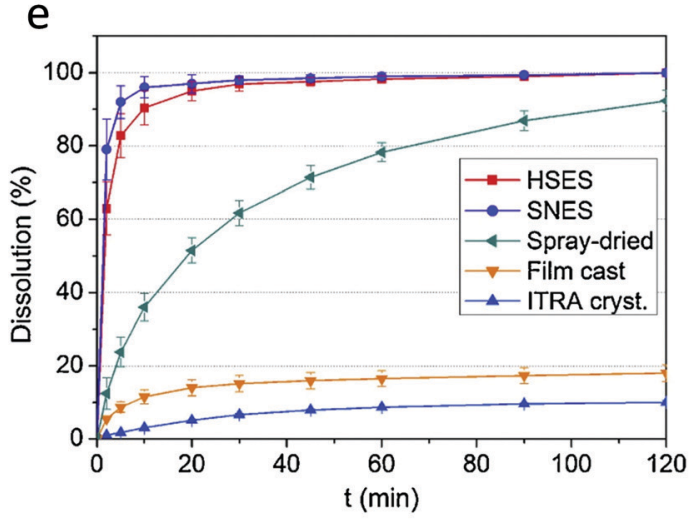

Fig. 11 Data obtained using monaxial and high speed corona electrospinning for the preparation of poly(vinyl pyrrolidone/vinyl acetate)/itraconazole (ITRA) fibres. Scanning electron microscopy images of (a) and (b) the monoaxial fibres, and (c) and (d) the high-speed fibres are shown together with (e) dissolution profiles of high-speed (HSES) and monoxial ES (SNES) fibres, compared with analogous spray-dried or film-cast formulations and the raw material. Adapted with permission from ref. 119 (Nagy et al. 2015). Copyright Elsevier.

only a small amount of polymer solution to be exposed at any one time. ${ }^{2}$

One promising needleless modality is the corona ES method pioneered by Molnar and co-workers. ${ }^{117}$ This uses a rotating spinneret, to which polymer solution is fed from a reservoir. A narrow gap at the edge of the spinneret permits Taylor cones to form and fibres to be generated while the majority of the polymer solution remains covered (Fig. 10). Amendments to the collector are also required for high-throughput electrospinning, and in most cases a conveyor-belt type collector is used (Fig. 10). In addition to the risks of fire from the large volumes of solvents used in high-throughput ES, environmental considerations are also important since there are toxicities associated with many common ES solvents.

A number of researchers have produced drug-loaded ES fibres on the large scale using the needleless approach. For instance, fibres have been prepared made of poly(vinyl alcohol) loaded with the antiretroviral drug tenofovir (yielding up to $7.7 \mathrm{~g}$ of product per hour), ${ }^{118}$ or poly(vinyl pyrrolidone/vinyl acetate) incorporating the antifungal itraconazole (450 g of product per hour).$^{119}$ Increasing the throughput rate is generally observed to lead to thicker fibres with larger diameters. It also reduces the homogeneity of the fibres, leading to larger variation in fibre diameters and more bead-on-string type morphologies (Fig. 11a-d). However, the functional performance is not affected to any significant extent by moving to a highspeed ES process (Fig. 11e). It has been shown that the products of high-throughput ES can be processed into tablets, ${ }^{120}$ and remain stable upon storage. ${ }^{121}$ It has even proven possible to integrate the steps of drug synthesis, ES, and post-processing into tablets in a single end-to-end process. ${ }^{122}$

Finally, we should note the importance of being able to prepare materials in GMP conditions for ES fibres to be able to move forward into the clinic. This requires robust quality control processes and working in clean-room conditions, but is eminently possible (although resource-intensive). There are studies in the literature which have generated ES materials to these stringent quality standards, ${ }^{123}$ and the company Bioinicia have a GMP-standard ES facility ${ }^{114}$ which has been used to prepare materials for clinical trials of the Rivelin patch formulation (to treat oral lichen planus) developed by Afyx. ${ }^{124,125}$ The results from these trials are very promising, which bodes extremely well for the future of ES formulations in the clinic.

That said, there are a number of challenges which must be overcome before electrospun products are ready for the clinic. More work is required to develop robust and reproducible protocols for production, and the number of studies looking at the high-throughput production of fibres by ES is still limited. Often in the literature toxic solvents are used in electrospinning, and for clinical applications it will be necessary to move to more benign solvents, and/or put in place robust procedures to ensure that all solvent is exhausted after spinning. Handling large volumes of toxic or flammable solvents in high-throughput processes is also difficult, and requires more work to ensure this is done safely and without damage to the environment. Ideally, solvent would be recycled back into the system to minimise waste. Beyond this, quality control standards and processes will be needed to ensure products with highly reproducible characteristics and which are safe and effective for patients.

\section{Conclusions and outlook}

The electrospinning (ES) process is a powerful route for the generation of polymer-based fibres with diameters on the nanoto micron-scale. A wide variety of functional components can be incorporated into these fibres, including small molecule drugs, proteins and cells. Multiple fluids can be processed simultaneously, yielding fibres with core/shell, Janus or more complex architectures. ES fibres can be employed for drug delivery (for instance to accelerate dissolution rate, target release to a particular part of the body, or prolong release for sustained 
treatment of a condition). They may furthermore be used for the diagnosis and imaging of disease, for simultaneous treatment and diagnosis ("theranostics"), and to regenerate damaged tissue such as nerves or bone. It is now possible to produce ES fibres on an industrial scale, and in GMP conditions. At least one ES product is now in clinical trials. In the view of the authors, after some years in the wilderness the ES technology is now on the cusp of making the leap into the clinic. In addition, there have recently been exciting developments in preparing short fibres and aerogels from electrospun products, in 3D electrospinning, in the development of increasingly complex architectures from multi-fluid processes, and in high-throughput production. These innovations are expected to continue into the future, leading to ever more tuneable and effective formulations.

\section{Author contributions}

All authors contributed to undertaking detailed literature research and the writing of this manuscript, with lead contributions to sections as follows: Karolina Dziemidowicz - electrospinning and proteins; Qingqing Sang - electrospinning of small molecule drugs; Jinglei Wu - tissue engineering; Ziwei Zhang - theranostic formulations; Fenglei Zhou - diagnosis and imaging; Jose M. Lagaron - scale up and clinical translation; Xiumei Mo - tissue engineering; Geoff J. M. Parker - diagnosis and imaging; DengGuang Yu - multi-fluid electrospinning of small molecule drugs; Li-Min Zhu - electrospinning of small molecule drugs; Gareth R. Williams - compilation of manuscript, introduction, conclusions and perspectives. All authors additionally reviewed and approved the final version of the manuscript.

\section{Conflicts of interest}

JML is founder of the spin-out company Bioinicia SL, which has commercial interests in the GMP manufacture and scale-up of electrospun formulations.

\section{Acknowledgements}

The authors thank the following for funding: the Engineering and Physical Sciences Research Council (PhD studentship to $\mathrm{KD}$ in the Centre for Doctoral Training in Advanced Therapeutics \& Nanomedicines; EP/L01646X/1); the Royal Society (International Exchanges Cost-Share grant IEC \NSFC $\backslash 181274$ to XM and GRW); and, the National Institute for Health Research University College London Hospitals Biomedical Research Centre (for the work of FZ and GJMP).

\section{References}

1 D. G. Yu, J. J. Li, G. R. Williams and M. Zhao, J. Controlled Release, 2018, 292, 91-110.

2 P. Vass, E. Szabó, A. Domokos, E. Hirsch, D. Galata, B. Farkas, B. Démuth, S. K. Andersen, T. Vigh, G. Verreck,
G. Marosi and Z. K. Nagy, Wiley Interdiscip. Rev.: Nanomed. Nanobiotechnol., 2019, 12, e1611.

3 A. Moreira, D. Lawson, L. Onyekuru, K. Dziemidowicz, U. Angkawinitwong, P. F. Costa, N. Radacsi and G. R. Williams, J. Controlled Release, 2020, DOI: 10.1016/ j.jconrel.2020.10.046.

4 N. Bhardwaj and S. C. Kundu, Biotechnol. Adv., 2010, 28, 325-347.

5 N. Bock, T. R. Dargaville and M. A. Woodruff, Prog. Polym. Sci., 2012, 37, 1510-1551.

6 T. D. Brown, P. D. Dalton and D. W. Hutmacher, Prog. Polym. Sci., 2016, 56, 116-166.

7 S. Chakraborty, I. C. Liao, A. Adler and K. W. Leong, Adv. Drug Delivery Rev., 2009, 61, 1043-1054.

8 X. Hu, S. Liu, G. Zhou, Y. Huang, Z. Xie and X. Jing, J. Controlled Release, 2014, 185, 12-21.

9 B. Kong and S. Mi, Materials, 2016, 9, 614.

10 S. Qi and D. Craig, Adv. Drug Delivery Rev., 2016, 100, 67-84. 11 C. J. Luo, S. D. Stoyanov, E. Stride, E. Pelan and M. Edirisinghe, Chem. Soc. Rev., 2012, 41, 4708-4735.

12 P. L. Soti, K. Bocz, H. Pataki, Z. Eke, A. Farkas, G. Verreck, E. Kiss, P. Fekete, T. Vigh, I. Wagner, Z. K. Nagy and G. Marosi, Int. J. Pharm., 2015, 494, 23-30.

13 R. Vehring, Pharm. Res., 2008, 25, 999-1022.

14 G. R. Williams, B. T. Raimi-Abraham and C. Luo, Nanofibres in Drug Delivery, UCL Press, 2018.

15 T. J. Sill and H. A. von Recum, Biomaterials, 2008, 29, 1989-2006.

16 D.-G. Yu, X.-X. Shen, C. Branford-White, K. White, L.-M. Zhu and S. W. A. Bligh, Nanotechnology, 2009, 20, 055104.

17 E. Adeli, J. Appl. Polym. Sci., 2015, 132, 42212.

18 C. Németh, B. Gyarmati, J. Gacs, D. V. Salakhieva, K. Molnár, T. Abdullin, K. László and A. Szilágyi, Eur. Polym. J., 2020, 130, 109624.

19 D.-G. Yu, C. Branford-White, X.-X. Shen, X.-F. Zhang and L.-M. Zhu, J. Dispersion Sci. Technol., 2010, 31, 902-908.

20 U. E. Illangakoon, H. Gill, G. C. Shearman, M. Parhizkar, S. Mahalingam, N. P. Chatterton and G. R. Williams, Int. J. Pharm., 2014, 477, 369-379.

21 K. Dziemidowicz, F. L. Lopez, B. J. Bowles, A. J. Edwards, T. B. Ernest, M. Orlu and C. Tuleu, AAPS PharmSciTech, 2018, 19, 2646-2657.

22 J. Xie and C. H. Wang, Pharm. Res., 2006, 23, 1817-1826.

23 L. Steffens, A. M. Morás, P. R. Arantes, K. Masterson, Z. Cao, M. Nugent and D. J. Moura, Eur. J. Pharm. Sci., 2020, 143, 105183.

24 C. Xie, R. Ding, X. Wang, C. Hu, J. Yan, W. Zhang, Y. Wang, Y. Qu, S. Zhang, P. He and Z. Wang, Nanotechnology, 2019, 31, 115101.

25 D. Mohsen, F. Hamid and R. Seeram, Mini-Rev. Med. Chem., 2020, 20, 1272-1286.

26 R. Contreras-Cáceres, L. Cabeza, G. Perazzoli, A. Díaz, J. M. López-Romero, C. Melguizo and J. Prados, Nanomaterials, 2019, 9, 656.

27 J. G. Edmans, K. H. Clitherow, C. Murdoch, P. V. Hatton, S. G. Spain and H. E. Colley, Pharmaceutics, 2020, 12, 504. 
28 X. Shen, D. Yu, L. Zhu, C. Branford-White, K. White and N. P. Chatterton, Int. J. Pharm., 2011, 408, 200-207.

29 U. E. Illangakoon, T. Nazir, G. R. Williams and N. P. Chatterton, J. Pharm. Sci., 2014, 103, 283-292.

30 M. Vlachou, S. Kikionis, A. Siamidi, S. Kyriakou, A. Tsotinis, E. Ioannou and V. Roussis, Pharmaceutics, 2019, 11, 480.

31 P. S. Giram, A. Shitole, S. S. Nande, N. Sharma and B. Garnaik, Mater. Sci. Eng., C, 2018, 92, 526-539.

32 Q. Sang, G. R. Williams, H. Wu, K. Liu, H. Li and L. M. Zhu, Mater. Sci. Eng., C, 2017, 81, 359-365.

33 J. Hu, H.-Y. Li, G. R. Williams, H.-H. Yang, L. Tao and L.-M. Zhu, J. Pharm. Sci., 2016, 105, 1104-1112.

34 H. Li, G. R. Williams, J. Wu, Y. Lv, X. Sun, H. Wu and L. M. Zhu, Int. J. Pharm., 2017, 517, 135-147.

35 H. Li, K. Liu, G. R. Williams, J. Wu, J. Wu, H. Wang, S. Niu and L. M. Zhu, Colloids Surf., B, 2018, 171, 142-149.

36 D.-G. Yu, M. Wang, X. Li, X. Liu, L.-M. Zhu and S. W. Annie Bligh, Wiley Interdiscip. Rev.: Nanomed. Nanobiotechnol., 2020, 12, e1601.

37 S. Labbaf, H. Ghanbar, E. Stride and M. Edirisinghe, Macromol. Rapid Commun., 2014, 35, 618-623.

38 A. K. Moghe and B. S. Gupta, Polym. Rev., 2008, 48, 353-377. 39 H. Zhou, Z. Shi, X. Wan, H. Fang, D. G. Yu, X. Chen and P. Liu, Nanomaterials, 2019, 9, 843.

40 C. L. He, Z. M. Huang, X. J. Han, L. Liu, H. S. Zhang and L. S. Chen, J. Macromol. Sci. B, 2006, 45, 515-524.

41 M. Jin, D. G. Yu, X. Wang, C. F. Geraldes, G. R. Williams and S. A. Bligh, Adv. Healthcare Mater., 2016, 5, 977-985.

42 D. Jia, Y. Gao and G. R. Williams, Int. J. Pharm., 2017, 523, 376-385.

43 Y. Su, Q. Su, W. Liu, G. Jin, X. Mo and S. Ramakrishna, J. Biomater. Sci., Polym. Ed., 2012, 23, 861-871.

44 D. G. Yu, L. M. Zhu, C. J. Branford-White, J. H. Yang, X. Wang, Y. Li and W. Qian, Int. J. Nanomed., 2011, 6, 3271-3280.

45 Y.-H. Wu, D.-G. Yu, X.-Y. Li, A.-H. Diao, U. E. Illangakoon and G. R. Williams, J. Mater. Sci., 2015, 50, 3604-3613.

46 D. Han and A. J. Steckl, ACS Appl. Mater. Interfaces, 2013, 5, 8241-8245.

47 M. Habibi Jouybari, S. Hosseini, K. Mahboobnia, L. A. Boloursaz, M. Moradi and M. Irani, Colloids Surf., B, 2019, 179, 495-504.

48 D. G. Yu, X. Y. Li, X. Wang, J. H. Yang, S. W. Bligh and G. R. Williams, ACS Appl. Mater. Interfaces, 2015, 7, 18891-18897.

49 D. Han, S. Sherman, S. Filocamo and A. J. Steckl, Acta Biomater., 2017, 53, 242-249.

50 Y. Geng, P. Zhang, Q. Wang, Y. Liu and K. Pan, J. Mater. Chem. B, 2017, 5, 5390-5396.

51 A. Khalf and S. V. Madihally, Eur. J. Pharm. Biopharm., 2017, 112, 1-17.

52 A. K. Ekaputra, G. D. Prestwich, S. M. Cool and D. W. Hutmacher, Biomaterials, 2011, 32, 8108-8117.

53 S. Seif, V. Planz and M. Windbergs, Arch. Pharm., 2017, 350, 1-8. 54 S. Awwad and U. Angkawinitwong, Pharmaceutics, 2018, 10, 83.

55 M. Yoshida, R. Langer, A. Lendlein and J. Lahann, J. Macromol. Sci. C, 2006, 46, 347-375.

56 B. Xia and Y. Lv, Mater. Sci. Eng., C, 2018, 82, 253-264.
57 N. G. Rim, S. J. Kim, Y. M. Shin, I. Jun, D. W. Lim, J. H. Park and H. Shin, Colloids Surf., B, 2012, 91, 189-197.

58 S. H. Ku and C. B. Park, Biomaterials, 2010, 31, 9431-9437.

59 Y. Liu, C. Xu, Y. Gu, X. Shen, Y. Zhang, B. Li and L. Chen, RSC Adv., 2019, 9, 11722-11736.

60 L. Vyslouzilova, M. Buzgo, P. Pokorny, J. Chvojka, A. Mickova, M. Rampichova, J. Kula, K. Pejchar, M. Bilek, D. Lukas and E. Amler, Int. J. Pharm., 2017, 516, 293-300.

61 T. Briggs and T. L. Arinzeh, J. Biomed. Mater. Res. A, 2014, 102, 674-684.

62 H. Frizzell, T. J. Ohlsen and K. A. Woodrow, Int. J. Pharm., 2017, 533, 99-110.

63 U. Angkawinitwong, S. Awwad, P. T. Khaw, S. Brocchini and G. R. Williams, Acta Biomater., 2017, 64, 126-136.

64 E. R. Pavlova, D. V. Bagrov, M. N. Kopitsyna, D. A. Shchelokov, A. P. Bonartsev, I. I. Zharkova, T. K. Mahina, V. L. Myshkina, G. A. Bonartseva, K. V. Shaitan and D. V. Klinov, J. Appl. Polym. Sci., 2017, 134, 45090.

65 J. Wang and M. Windbergs, Int. J. Pharm., 2019, 556, 363-371.

66 E. Ehler and S. N. Jayasinghe, Analyst, 2014, 139, 4449-4452.

67 S. L. Sampson, L. Saraiva, K. Gustafsson, S. N. Jayasinghe and B. D. Robertson, Small, 2014, 10, 78-82.

68 S. N. Jayasinghe, Analyst, 2013, 138, 2215-2223.

69 P. P. Mane, R. S. Ambekar and B. Kandasubramanian, Int. J. Pharm., 2020, 583, 119364.

70 N.-H. Kim, S.-J. Choi, D.-J. Yang, J. Bae, J. Park and I.-D. Kim, Sens. Actuators, B, 2014, 193, 574-581.

71 Y. Dror, W. Salalha, R. Avrahami, E. Zussman, A. L. Yarin, R. Dersch, A. Greiner and J. H. Wendorff, Small, 2007, 3, 1064-1073.

72 A. Arinstein and E. Zussman, Phys. Rev. E, 2007, 76, 056303.

73 R. Halaui, A. Moldavsky, Y. Cohen, R. Semiat and E. Zussman, J. Membrane Sci., 2011, 379, 370-377.

74 D. Han and A. J. Steckl, ChemPlusChem, 2019, 84, 1453-1497.

75 F.-L. Zhou, P. L. Hubbard, S. J. Eichhorn and G. J. M. Parker, Polymer, 2011, 52, 3603-3610.

76 A. Sitt, J. Soukupova, D. Miller, D. Verdi, R. Zboril, H. Hess and J. Lahann, Small, 2016, 12, 1432-1439.

77 C.-T. Pan, C.-K. Yen, S.-Y. Wang, Y.-C. Lai, L. Lin, J. C. Huang and S.-W. Kuo, RSC Adv., 2015, 5, 85073-85081.

78 H. Yuan, J. Qin, J. Xie, B. Li, Z. Yu, Z. Peng, B. Yi, X. Lou, X. Lu and Y. Zhang, Nanoscale, 2016, 8, 16307-16322.

79 F.-L. Zhou, G. J. M. Parker, S. J. Eichhorn and P. L. Hubbard Cristinacce, Mater. Charact., 2015, 109, 25-35.

80 D. Liewald, R. Miller, N. Logothetis, H.-J. Wagner and A. Schüz, Biol. Cybern., 2014, 108, 541-557.

81 I. Teh, F.-L. Zhou, P. L. Hubbard Cristinacce, G. J. M. Parker and J. E. Schneider, J. Magn. Reson. Imaging, 2016, 43, 594-600.

82 D. S. Novikov, E. Fieremans, S. N. Jespersen and V. G. Kiselev, NMR Biomed., 2019, 32, e3998.

83 B. Wang, M. E. Tedder, C. E. Perez, G. Wang, A. L. de Jongh Curry, F. To, S. H. Elder, L. N. Williams, D. T. Simionescu and J. Liao, J. Mater. Sci.: Mater. Med., 2012, 23, 1835-1847. 
84 J. B. Partridge, M. H. Smerup, S. E. Petersen, P. F. Niederer and R. H. Anderson, Heart, 2014, 100, 1289.

85 R. Kojima, D. Aubel and M. Fussenegger, Curr. Opin. Chem. Biol., 2015, 28, 29-38.

86 S. K. Turan, H. Yildizhan, N. P. Barkan, F. D. Ö. Demiralp, B. Uslu and S. A. Ozkan, in Design of Nanostructures for Theranostics Applications, Elsevier, 2018, pp. 1-40.

87 M. Angelakeris, Biochim. Biophys. Acta, Gen. Subj., 2017, 1861, 1642-1651.

88 Q. Li, L. Ge, W. Wan, J. Jiang, W. Zhong, J. Ouyang and M. Xing, Tissue Eng., Part C, 2015, 21, 1024-1034.

89 R. Ramachandran, V. R. Junnuthula, G. S. Gowd, A. Ashokan, J. Thomas, R. Peethambaran, A. Thomas, A. K. K. Unni, D. Panikar, S. V. Nair and M. Koyakutty, Sci. Rep., 2017, 7, 43271.

90 H. Singh, W. Li, M. R. Kazemian, R. Yang, C. Yang, S. Logsetty and S. Liu, ACS Appl. Bio Mater., 2019, 2, 2028-2036.

91 M. Jin, D.-G. Yu, C. F. G. C. Geraldes, G. R. Williams and S. W. A. Bligh, Mol. Pharm., 2016, 13, 2457-2465.

92 Z. Zhang, C. J. R. Wells, A. M. King, J. C. Bear, G. L. Davies and G. R. Williams, J. Mater. Chem. B, 2020, 8, 7264-7274.

93 A. Keirouz, M. Chung, J. Kwon, G. Fortunato and N. Radacsi, Wiley Interdiscip. Rev.: Nanomed. Nanobiotechnol., 2020, 12, e1626.

94 X. Wang, B. Ding and B. Li, Mater. Today, 2013, 16, 229-241.

95 V. Perez-Puyana, M. Jiménez-Rosado, A. Romero and A. Guerrero, Polymers, 2020, 12, 1566.

96 J. Zhu, D. Chen, J. Du, X. Chen, J. Wang, H. Zhang, S. Chen, J. Wu, T. Zhu and X. Mo, Compos. B Eng., 2020, 186, 107788.

97 J. Fang, J. Zhang, J. Du, Y. Pan, J. Shi, Y. Peng, W. Chen, L. Yuan, S.-H. Ye and W. R. Wagner, ACS Appl. Mater. Interfaces, 2016, 8, 14442-14452.

98 J. Wang, Y. Cheng, L. Chen, T. Zhu, K. Ye, C. Jia, H. Wang, M. Zhu, C. Fan and X. Mo, Acta Biomater., 2019, 84, 98-113.

99 M. L. D. Rayner, A. Grillo, G. R. Williams, E. Tawfik, T. Zhang, C. Volitaki, D. Q. M. Craig, J. Healy and J. B. Phillips, J. Neural Eng., 2020, 17, 046030.

100 Y. Si, J. Yu, X. Tang, J. Ge and B. Ding, Nat. Commun., 2014, 5, 5802 .

101 T. Xu, J. M. Miszuk, Y. Zhao, H. Sun and H. Fong, Adv. Healthcare Mater., 2015, 4, 2238-2246.

102 L. Weng, S. K. Boda, H. Wang, M. J. Teusink, F. D. Shuler and J. Xie, Adv. Healthcare Mater., 2018, 7, 1701415.

103 W. Chen, S. Chen, Y. Morsi, H. El-Hamshary, M. El-Newhy, C. Fan and X. Mo, ACS Appl. Mater. Interfaces, 2016, 8, 24415-24425.

104 Y. Chen, M. Shafiq, M. Liu, Y. Morsi and X. Mo, Bioact. Mater., 2020, 5, 963-979.
105 M. Vong, E. Speirs, C. Klomkliang, I. Akinwumi, W. Nuansing and N. Radacsi, RSC Adv., 2018, 8, 15501-15512.

106 B. Feng, S. Wang, D. Hu, W. Fu, J. Wu, H. Hong, I. J. Domian, F. Li and J. Liu, Acta Biomater., 2019, 83, 211-220.

107 S. Liu, F. Wu, S. Gu, T. Wu, S. Chen, S. Chen, C. Wang, G. Huang, T. Jin, W. Cui, B. Sarmento, L. Deng and C. Fan, Adv. Sci., 2018, 6, 1801217.

108 S. Liu, C. Hu, F. Li, X.-J. Li, W. Cui and C. Fan, Tissue Eng., Part A, 2013, 19, 529-537.

109 X. Liu, X. He, D. Jin, S. Wu, H. Wang, M. Yin, A. Aldalbahi, M. El-Newehy, X. Mo and J. Wu, Acta Biomater., 2020, 108, 207-222.

110 X. Yan, M. Yu, S. Ramakrishna, S. J. Russell and Y.-Z. Long, Nanoscale, 2019, 11, 19166-19178.

111 L. Persano, A. Camposeo, C. Tekmen and D. Pisignano, Macromol. Mater. Eng., 2013, 298, 504-520.

112 S. A. Theron, A. L. Yarin, E. Zussman and E. Kroll, Polymer, 2005, 46, 2889-2899.

113 A. Varesano, F. Rombaldoni, G. Mazzuchetti, C. Tonin and R. Comotto, Polym. Int., 2010, 59, 1606-1615.

114 https://bioinicia.com/pharma/.

115 S. Petrik, in Nanofibers - Production, Properties and Functional Applications, ed. T. Lin, InTech, Rijeka, 2011, ch. 1, pp. 3-16.

116 https://www.elmarco.com/.

117 K. Molnar and Z. K. Nagy, Eur. Polym. J., 2016, 74, 279-286.

118 E. A. Krogstad and K. A. Woodrow, Int. J. Pharm., 2014, 475, 282-291.

119 Z. K. Nagy, A. Balogh, B. Demuth, H. Pataki, T. Vigh, B. Szabo, K. Molnar, B. T. Schmidt, P. Horak, G. Marosi, G. Verreck, I. Van Assche and M. E. Brewster, Int. J. Pharm., 2015, 480, 137-142.

120 B. Demuth, A. Farkas, A. Balogh, K. Bartosiewicz, B. KallaiSzabo, J. Bertels, T. Vigh, J. Mensch, G. Verreck, I. Van Assche, G. Marosi and Z. K. Nagy, J. Pharm. Sci., 2016, 105, 2982-2988.

121 B. Demuth, A. Farkas, H. Pataki, A. Balogh, B. Szabo, E. Borbas, P. L. Soti, T. Vigh, E. Kiserdei, B. Farkas, J. Mensch, G. Verreck, I. Van Assche, G. Marosi and Z. K. Nagy, Int. J. Pharm., 2016, 498, 234-244.

122 A. Balogh, A. Domokos, B. Farkas, A. Farkas, Z. Rapi, D. Kiss, Z. Nyiri, Z. Eke, G. Szarka, R. Örkényi, B. Mátravölgyi, F. Faigl, G. Marosi and Z. K. Nagy, Chem. Eng. J., 2018, 350, 290-299.

123 M. A. Alamein, Q. Liu, S. Stephens, S. Skabo, F. Warnke, R. Bourke, P. Heiner and P. H. Warnke, Adv. Healthcare Mater., 2013, 2, 702-717.

124 https://afyxtx.com/.

125 https:/clinicaltrials.gov/ct2/show/NCT03592342. 